3. EUR-Lex [Internet]. Luxembourg: Publications Office of the European Union; c2009 [updated 2009 Nov 12; cited 2009 Oct 10]. Council Directive 93/ 104/EC of 23 November 1993 concerning certain aspects of the organization of working time; [about 1 screen]. Available from: http://eur-lex.europa.eu/ LexUriServ/LexUriServ.do?uri=CELEX:31993L01 04:EN:HTML

doi:10.1016/j.jtcvs.2009.09.060

\section{INTRA-ATRIAL REROUTING BY THE POSTERIOR LEFT ATRIAL WALL FLAP FOR TOTAL ANOMALOUS PULMONARY VENOUS RETURN DRAINAGE INTO THE CORONARY SINUS IN NEONATES \\ To the Editor:}

We read with great interest the new procedure for total anomalous pulmonary venous return (TAPVR) drainage into the coronary sinus (CS), which Yamagishi and colleagues ${ }^{1}$ successfully performed for an infant weighing $5.5 \mathrm{~kg}$. Briefly, the roof of the CS was incised toward the left atrium (LA) to create a flap from the posterior wall of the LA (= the anterior wall of the common chamber and the CS). The flap thus created was then moved anteriorly to cover the entire atrial communication and the CS orifice. However, we were unable to find any follow-up reports on this procedure. We recently successfully performed this procedure for 2 neonatal cases and recognized several important features associated with this surgery.

\section{CASE 1}

A baby girl with a birth weight of $2.7 \mathrm{~kg}$ underwent this new procedure for TAPVR drainage into the CS at 8 days of age. She was discharged on postoperative day 22 without any complications. Postoperative echocardiogram demonstrated a large communication between the LA and the common chamber (Figure 1, A). An abnormal continuous flow was detected at the superior wall of the CS. This flow was directed toward the common chamber and appeared to be a small coronary arterial flow (Figure $1, B)$. This abnormal flow disappeared 2 months after the operation. One year after the operation, the patient was doing well with no evidence of arrhythmia.

\section{CASE 2}

The new procedure was also performed on a 20-day-old baby girl (birth weight, $3.0 \mathrm{~kg}$ ) who had
TAPVR drainage into the CS. Because the posterior wall flap of the LA was not sufficiently large to cover the entire atrial septal defect and CS orifice, a fresh autologous pericardial patch was applied to close the rest of the atrial communication. At 1 year and 7 months after the operation, she is in good clinical status with no arrhythmia.

The usual surgical treatment for TAPVC to the CS is either the CS cut-back procedure or the Van Praagh technique. $^{2}$ The advantages of this new procedure compared with these previously performed procedures are as follows:

1. Sufficiently wide communication between the LA and the common chamber can be obtained.

2. Neither prosthetic materials nor autologous pericardium is required for closing the atrial communication and the CS orifice.

However, the following cautionary points should be noted:

1. During making the CS anterior wall flap, the incision line may enter into the pulmonary venous orifices.

2. Anastomosing the flap to the anterior edge of the CS orifice may damage the atrioventricular node.
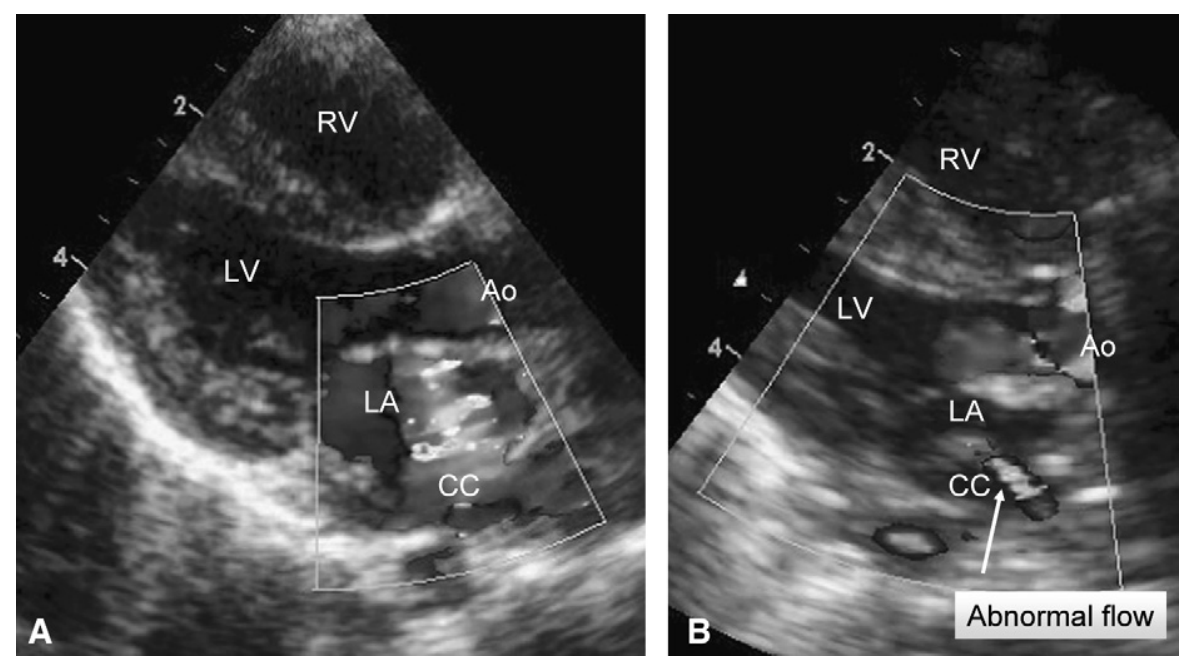

FIGURE 1. A, Echocardiogram after surgery. Parasternal long-axis view during the diastolic phase showing a large communication between the LA and the common chamber. B, Another parasternal long-axis view showing an abnormal continuous flow from the posterior wall of the new LA toward the common chamber. $R V$, Right ventricle; $L V$, left ventricle; $A o$, aorta; $L A$, left atrium; $C C$, common chamber. 
3. In a neonatal case with a common chamber located inferiorly, a sufficiently large flap cannot be created to completely cover the atrial communication.

4. Insufficient anastomosis between the intima of common chamber and the endocardium in the LA may cause a coronary artery steal.

5. Late postoperative atrial arrhythmia is unknown.

We believe that this new procedure is applicable even in neonatal cases with TAPVC drainage into the CS. However, a long observation period will be required for those patients who undergo this new procedure.

Mitsugi Nagashima, MD

Fumiaki Shikata, MD

Kanji Kawachi, MD

Department of Surgery

Division of Cardiothoracic Surgery and Regenerative Surgery

Stroke and Cardiovascular Center

Ehime University School of Medicine Shitsukawa, Toon City, Japan

\section{References}

1. Yamagishi M, Shuntoh K, Takahashi A, Shinkawa T, Miyazaki T, Kitamura N. Intra-atrial rerouting by transference of the posterior left atrial wall for cardiac-type total anomalous pulmonary venous return. J Thorac Cardiovasc Surg. 2002; 123:996-9.

2. Van Praagh R, Harken AH, Delisle G, Ando M, Gross RE. Total anomalous pulmonary venous drainage to the coronary sinus: a revised procedure for its correction. J Thorac Cardiovasc Surg. 1972;64:132-5.

doi:10.1016/j.jtcvs.2009.10.055

\section{Reply to the Editor:}

I thank Dr Nagashima and colleagues for their insightful comments on our new surgical technique for cardiactype total anomalous pulmonary venous drainage (TAPVD). ${ }^{1}$ Pulmonary venous obstruction (PVO) is an inevitable, serious complication after the repair of cardiac-type TAPVR by conventional surgical techniques. ${ }^{2,3}$ Turbulent blood flow at the warped pulmonary venous pathway through the coronary sinus ${ }^{2}$ or a narrow communication between the pulmonary venous channel and the left atrium ${ }^{3}$ may cause intimal proliferation followed by PVO. Although the coronary sinus is usually dilated in cardiac-type TAPVD, it is by no means wide enough to serve as the permanent pulmonary venous pathway. In contrast, the posterior wall transference technique $^{1}$ can create laminar pulmonary venous blood flow through a wide and straight communication into the left atrium.

With the posterior wall transference technique, the common wall between the left atrium and the pulmonary venous chamber is cut out as a tonguelike flap. It is also important not to cut the pulmonary venous orifice to avoid postoperative PVO. Ordinarily, it should be possible to incise the posterior left atrial wall while preserving the pulmonary venous orifices, because the pulmonary venous orifices are clearly visible during the procedure.

The roof of the coronary sinus and posterior wall of the left atrium is applied to a new atrial septum with the posterior wall transference technique. To avoid damage to the atrioventricular node, the roof of the coronary sinus should not be cut longitudinally along its caudal edge but along little to the middle. The right atrial portion of the roof of the coronary sinus can then be safely anastomosed to the floor of the coronary sinus far away from the atrioventricular node.

The neonatal posterior left atrial wall is certainly a rather small area. Indeed, a small posterior left atrial wall flap would be insufficient to completely fill the atrial septal defect. A supplementary autologous pericardial patch is necessary in such cases. The pericardial patch will not cause PVO, because the patch is used to fill the residual atrial septal defect rather than to construct the pulmonary venous pathway. Furthermore, stenosis at the junction of the common pulmonary chamber with the coronary sinus or within the coronary sinus is rare. ${ }^{4}$
PVO is not usually exacerbated during the neonatal period in cardiac-type TAPVD. The posterior wall transference technique ${ }^{1}$ is easily performed in infancy. Therefore, risky emergency surgical intervention is unnecessary for neonates without signs of PVO.

Nagashima and colleagues also pointed out postoperative abnormal coronary artery flow toward the atrium. This excursive complication does not arise from a deficiency of the posterior wall transference technique. Mural coronary artery steal is certainly avoidable by adequate firm anastomosis of the atrial wall.

Three infants with cardiac type TAPVD underwent repair by the posterior wall transference technique at our institution. Ages at the time of operation were 2, 4, and 6 months. Body weights ranged from 3.9 to $5.5 \mathrm{~kg}$. The follow-up period ranged from to 22 to 70 months. No arrhythmias were seen on postoperative electrocardiography. Postoperative echocardiograms demonstrated a wide pulmonary venous pathway without stenosis. The posterior wall transference technique for cardiac-type TAPVD is a useful surgical option without the complications of late PVO and arrhythmias.

Masaaki Yamagishi, MD, PhD Department of Pediatric Cardiovascular Surgery

Children's Research Hospital Kyoto Prefectural University of Medicine Kyoto, Japan

\section{References}

1. Yamagishi M, Shuntoh K, Takahashi A, Shinkawa T, Miyazaki T, Kitamura N. Intra-atrial rerouting by transference of the posterior left atrial wall for cardiac-type total anomalous pulmonary venous return. J Thorac Cardiovasc Surg. 2002; 123:996-9

2. Stark J. Anomalous pulmonary venous return and cor triatriatum. In: Stark J, de Leval M, eds. Surgery for Congenital Heart Defects. 2nd ed. Philadelphia, PA: WB Saunders; 1994:329-42.

3. Van Praagh R, Harken AH, Delisle G, Ando M0, Gross RE. Total anomalous pulmonary venous drainage to the coronary sinus: a revised procedure for its connection. J Thorac Cardiovasc Surg. 1972;64:132-5

4. Geva T, Van Praagh S. Anomalous of the pulmonary veins. In: Allen HD, Driscoll DJ, Shaddy RE, 